\title{
Polymer-dispersant-stabilized Ag nanofluids for heat transfer applications
}

\author{
K. S. Pavithra ${ }^{1} \cdot$ S. C. Gurumurthy ${ }^{2} \cdot$ M. P. Yashoda ${ }^{1}\left(\right.$ Tarun $^{2} \cdot$ Mateti $^{3} \cdot$ Koduri Ramam $^{4} \cdot$ Roopa Nayak $^{5} \cdot$ M. S. Murari $^{6}$
}

Received: 10 December 2019 / Accepted: 10 July 2020 / Published online: 24 July 2020

(c) The Author(s) 2020

\section{Abstract}

One-step wet chemical method has been employed for the synthesis of silver (Ag) nanofluids followed by the preparation of polyvinyl pyrrolidone (PVP), polyvinyl alcohol (PVA) and PVP-PVA mixed-dispersant-stabilized nanofluids by varying the concentration ratio of dispersants for the viscosity and thermal conductivity analysis. The optical absorption studies indicate the presence of nanoparticles in the prepared fluids (or the formation of the silver nanoparticles). The shape and size of the nanoparticles are confirmed by the field emission scanning electron microscopy, and the particle size distribution and zeta potential analysis were carried out by using dynamic light scattering. It is observed that the thermal conductivity of Ag nanofluids increases with an increase in the dispersant concentration with respect to the temperature. The maximum thermal conductivity enhancement of Ag nanofluids was observed in the presence of an equimolar ratio of PVP-PVA (1:1:1) blends as stabilizers.

\section{Graphic abstract}

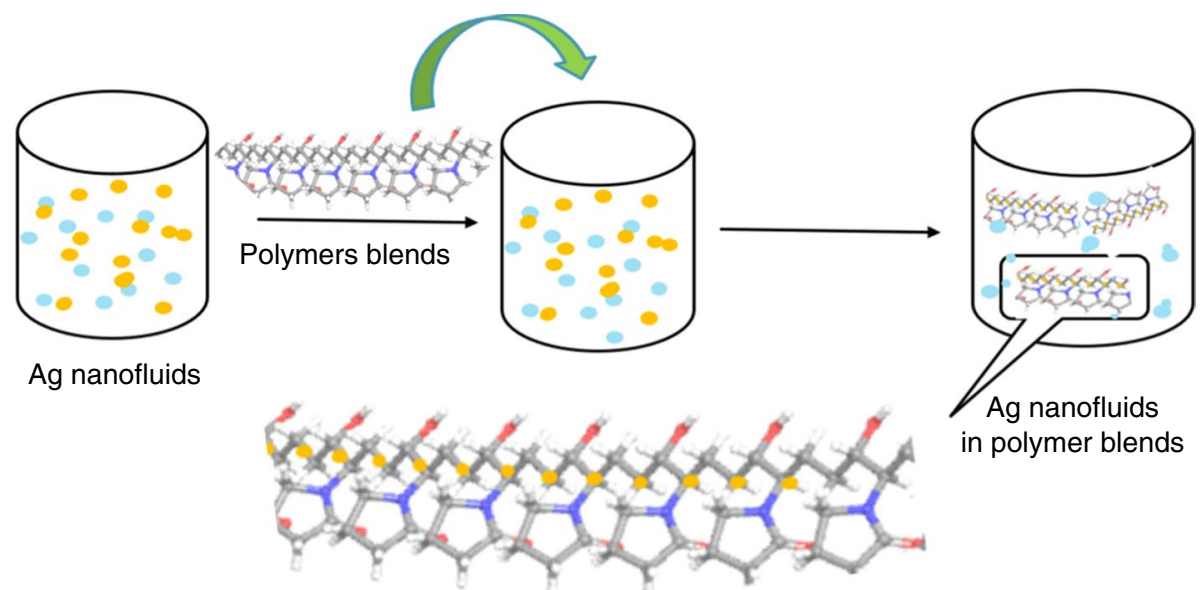

Keywords Silver nanofluids $\cdot$ Dispersants $\cdot$ Viscosity $\cdot$ Thermal conductivity

\section{List of symbols}

$k \quad$ Thermal conductivity/ $/ \mathrm{W} \mathrm{m}^{-1} \mathrm{~K}$

$k_{\mathrm{B}} \quad$ Boltzmann constant

$C_{\mathrm{p}} \quad$ Specific heat capacity

$T$ Temperature/K

$U$ Uncertainty

M. P. Yashoda

yashoda.mp@manipal.edu

Extended author information available on the last page of the article $\vartheta \quad$ Dynamic viscosity/Pa s

$\varphi \quad$ Nanoparticle volume fraction

$f \quad$ Base fluid

nf Nanofluid

$r_{\mathrm{c}} \quad$ Apparent radius of cluster/A

$k_{\mathrm{nf}} \quad$ Thermal conductivity of nanofluid

$k_{\mathrm{f}} \quad$ Thermal conductivity of base fluid

$k_{\text {eff }}$ Effective thermal conductivity of nanofluids

$k_{\mathrm{p}} \quad$ Thermal conductivity of particle 


\section{Introduction}

In recent advancements in technologies and industrial applications, there is a need for the development of highly efficient heat transfer and cooling devices. One of the decisive factors in industrial applications is to overcome the excess of heat production during the operation process and also to increase the reliability, thermal performance as well as working life of heat transfer devices [1]. Nanofluids are a colloidal suspension of ultrafine solid nanoparticles (NPs) like $\mathrm{Cu}, \mathrm{Zn}, \mathrm{Ag}, \mathrm{ZnO}, \mathrm{CuO}, \mathrm{TiO}_{2}$, etc., into the conventional heat transfer fluids like ethylene glycol, water, and engine oils. It has been proved as one of the efficient ways to improve the thermal performance of the system by the addition of NPs into the conventional fluids, and hence, it is considered as one of the significant potential materials for heat transfer applications. Therefore, nanofluids have attracted special interest due to their potential benefits for numerous applications such as biomedical applications [2], fuel cells [3], heat transfer [4], photocatalytic [5], bioactive materials [6], supercapacitors [7] and gas sensor [8].

Among the metal NPs, Ag NPs have attracted the attention of researchers for the preparation of nanofluids mainly due to their environmentally friendly and unique thermal properties. However, the strong van der Waals interaction and high surface energy of the NPs effortlessly form aggregates, and this leads to an instability of the system, which results in limiting the thermo-physical properties of the nanofluids [9]. Therefore, the stability of nanofluids is one of the critical issues and the main challenge to be solved for many applications [10].

Dispersion and stability are the key factors for the enhancement of the thermal conductivity of nanofluids. Further, uniform dispersion and stable suspension of NPs in fluids are the most important issue for the usage of nanofluids in various applications [11]. Therefore, many studies are conducted to produce more stable suspensions and also to enhance the thermal conductivity of nanofluids. Among the various nanofluids preparation techniques, the addition of dispersants plays an effective role in homogeneous dispersion of NPs in the base fluids by ensuring higher stability. The addition of dispersant is essential in altering the thermo-physical properties of the nanofluids, such as viscosity and thermal conductivity [12-15]. Murshed et al. [16] observed the enhancement of $29.7 \%$ in thermal conductivity of $5 \mathrm{vol} \%$ of $\mathrm{TiO}_{2}$ nanoparticle (size of $15 \mathrm{~nm}$ ) with CTAB (0.02 vol\%). Similarly, Saleh et al. investigated the impact of SDS, CTAB, and Span-80, surfactant on thermal properties of $\mathrm{TiO}_{2}$ nanofluids [17, 18]. They achieved 10.5, 11 and $12.5 \%$ enhancement in thermal conductivity for these surfactants with 1 vol\%, and they reported the enhancement only up to $7.5 \%$ in the absence of dispersants. Therefore, it is concluded that the addition of dispersants helps to minimize the particle aggregation and to enhance stability. A slight variation in thermal conductivity may be due to morphological changes of nanoparticles.

Literature survey revealed that various dispersants were utilized for stabilization of nanofluids for heat transfer applications such as PVP (polyvinyl pyrrolidone) and PVA (polyvinyl alcohol) [19, 20], SDS (sodium dodecyl sulphate) [21, 22], Gemini [23], Oleic acid [24], SDBS (sodium dodecylbenzene sulphate) [25], etc. Further, Babitha et al. have reported the requirement of higher dispersant concentration to obtain a stable dispersion of CNT (carbon nanotubes) with an increase in viscosity, which, in turn, requires higher energy to pump the nanofluids to the heat transfer system [26].

In addition to that, the dispersants would easily form foam during the heating and cooling process for heat transfer applications. It might be responsible for the reduction in the thermal performance of the fluids. Hence, there is a need for the development of a dispersant system that can reduce the formation of foam as well as adhesion. Wusiman et al. [27] observed a decrease in the thermal conductivity of nanofluid with an increase in the concentration of sodium dodecylbenzene sulphonate (SDBS) and sodium dodecyl sulphate (SDS) surfactants. Here, CNT nanofluid with SDBS exhibited better thermal conductivity than that with SDS dispersant. Further, they reported that the proper mixture ratio of CNT (0.5 mass\%) nanofluid with SDBS $(0.25$ mass\%) at $\mathrm{pH}(\sim 9)$ showed still better performance (total $2.8 \%$ increase) on thermal conductivity compared to base fluid (distilled water).

A similar trend was observed using mixed dispersant (anionic and cationic) in micellization, adsorption, and partitioning of non-ionic dispersant, and superior thermo-physical properties were observed than using individual dispersants. Acosta et al. [28] studied the effect and efficiency of dispersants for the dispersion of CNT (carbon nanotubes) in water as a base medium using mixtures of sodium dodecylbenzene sulphonate (SDBS) and gum arabic (GA). It is reported that mixed dispersants exhibit enhanced stability and thermal conductivity. PVP and PVA are the commonly used polymer dispersants for the stabilization of nanofluids in the polar solvents. To date, according to the author's knowledge, the literature reported on the preparation of $\mathrm{Ag}$ nanofluids using blended dispersants on thermal conductivity studies for heat transfer applications is very limited. In this context, further studies are required to understand the thermal conductivity properties of nanofluids in blended dispersants.

In the present work, we are using PVA, PVP and blended PVP-PVA polymer dispersants in order to evaluate the effect of dispersant concentration on the thermal conductivity of 
Ag nanofluids using water as base fluid. PVA and PVP are the synthetic water-soluble polymers with excellent dispersion properties. These are miscible in all ratios/concentrations, due to the hydrogen bonding between the carbonyl group present in the pyrrolidone rings of the PVP and hydroxyl groups of the PVA. Indeed, the blending of PVP-PVA polymers exhibits amphiphilic characteristics in case hydrophobic part (pyrrolidone moiety) is strongly adsorbed on the surface of the metal core and hydrophilic chain (hydroxyl moiety in the PVA), which creates a steric hindrance effect, which may lead to the dispersion of NPs in the fluids [29]. This study provides a convenient way to optimize the dispersant concentration for the preparation of stable nanofluids and a detailed study of thermal conductivity for heat transfer applications.

\section{Experimental}

\section{Materials}

Silver nitrate $\left(\mathrm{AgNO}_{3} \cdot 5 \mathrm{H}_{2} \mathrm{O}\right)$, sodium citrate $\left(\mathrm{Na}_{3} \mathrm{C}_{6} \mathrm{H}_{5} \mathrm{O}\right)$, PVA (molecular weight-35,000 $\mathrm{g} \mathrm{mol}^{-1}$ ) and PVP (molecular weight $-50,000 \mathrm{~g} \mathrm{~mol}^{-1}$ ) analytic-grade chemicals were procured from Loba Chemie, Alfa Aesar, Sisco Research Laboratories India. Chemicals were used without any further purification. Double distilled water was used throughout the experiments.

\section{Methods}

\section{Synthesis of Ag nanofluids}

Silver nanofluids were prepared by the wet chemical method using Lee and Meisel technique [24] by dissolving $1 \mathrm{mM}$ $\mathrm{AgNO}_{3} \cdot 5 \mathrm{H}_{2} \mathrm{O}$ (precursor) in $15 \mathrm{~mL}$ of distilled water in a beaker. Meanwhile, $5 \mathrm{mM}$ reducing agent solution was prepared by adding $\mathrm{Na}_{3} \mathrm{C}_{6} \mathrm{H}_{5} \mathrm{O}_{7}$ to distilled water in another beaker. It is kept for stirring at a temperature of $30^{\circ} \mathrm{C}$ using an IKA C-MAG HS 7 magnetic stirrer with a rotational speed of 350 RPM (rotations per minute) for about $30 \mathrm{~min}$. The solution is then added into the beaker containing precursor solution under vigorous stirring using a glass rod and heating at $90{ }^{\circ} \mathrm{C}$ until the colour of the solution changes from colourless to pale yellow. The colloidal solution is then cooled down to room temperature.

\section{Preparation of polymer blends}

The polymer blends were prepared by the solution blending technique. In the preparation of blends, two polymers (PVA and PVP) are dissolved in the same solvent separately and then solutions are mixed and/or brought to equilibrium. This method offers many advantages over other methods, which eliminates or minimizes the problem of incomplete mixing, the chemical change caused by heat and shear gradient, and colour degradation. In order to evaluate the effect of dispersants on Ag nanofluids, the solutions of PVA and PVP were prepared, respectively, by dissolving $10 \mathrm{gm}$ in $30 \mathrm{~mL}$ of distilled water in separate beakers and later mixed. The specific volume constant $(15 \mathrm{~mL})$ of $\mathrm{Ag}$ nanofluids was taken in a beaker with varying the dispersant ratio of PVA and PVP in the following order 1:1, 1:2, 1:3, 1:4 and 1:5. (The antecedents are the volume of PVA and PVP, and the consequents are the volumes of the Ag nanofluid.) Similarly, Ag/PVA-PVP polymer-blended samples were prepared in the ratio $1: 1: 1,1: 1.5: 0.5$ and $1: 0.5: 1.5$ for the thermal conductivity measurement suitable for the heat transfer applications.

\section{Characterizations}

\section{Microstructure, particle size, and spectroscopic studies}

Morphology and elemental composition of Ag nanofluids were recorded by the field emission scanning electron microscope and the energy-dispersive X-ray diffraction analyser (FESEM; Carl Zeiss; EVO-18). A few drops of the Ag nanofluid were dispersed in isopropyl alcohol and ultrasonicated for $5 \mathrm{~min}$. A small drop of sample was put on a carbon tape and vacuumdried for $2 \mathrm{~h}$. A similar procedure is followed for blended-polymer-dispersant-stabilized Ag nanofluids. The average particle distribution and zeta potential of Ag nanofluids were recorded by dynamic light scattering (DLS; Malvern; Nano-ZS90). The analysis was conducted at $25{ }^{\circ} \mathrm{C}$, with freshly prepared test sample using the milli-Q water (Merck Millipore company) in the ratio 1:10. (10 $\mu \mathrm{L}$ of nanofluid is diluted with $990 \mu \mathrm{L}$ of milli-Q water.) An absorbance of Ag nanofluids was recorded by the Shimadzu-1800 UV-Vis spectrophotometer.

\section{Thermal conductivity measurement of Ag nanofluids}

The thermal conductivity of $\mathrm{Ag}$ nanofluids was measured using a thermal property analyser KD2 Pro (Decagon Devices, USA). It is equipped with a $60-\mathrm{mm}$ probe that acts as a heating element as well as a thermistor. The probe is connected to a microprocessor to control and perform the measurements. To gauge the error in the experiment, the device was calibrated with glycerine provided with the equipment.

\section{Results and discussion}

\section{Optical and morphological studies}

Metal nanoparticles can absorb electromagnetic radiation, resulting in surface plasmon resonance. The intensity and 
position of the resonance wavelength of metal nanoparticles are strongly dependent on the amount, particle size, particle shape, and also on the surrounding medium [30, 31]. The $\mathrm{UV}-\mathrm{Vis}$ absorption spectra for Ag nanofluids recorded by

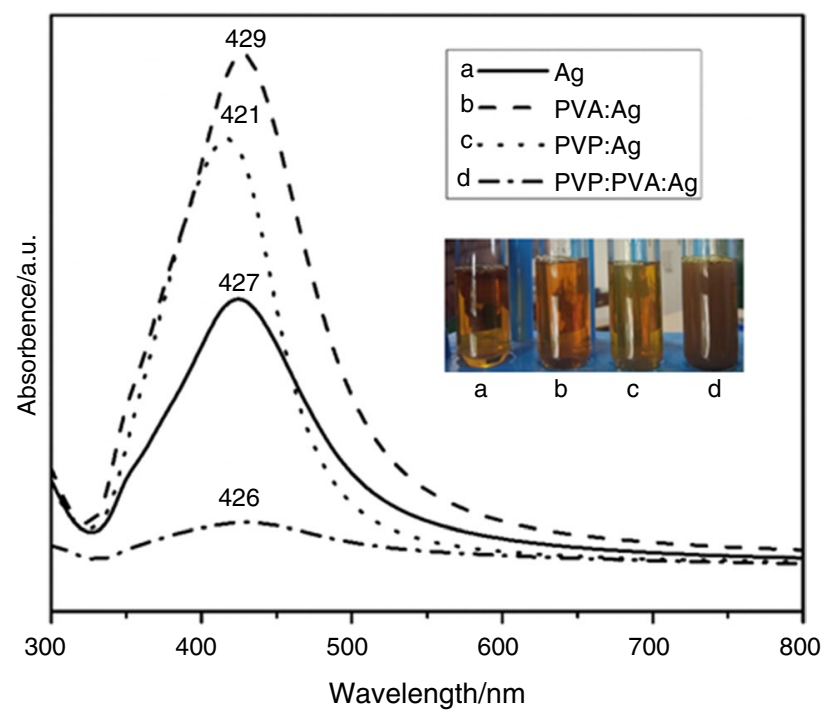

Fig. 1 UV-Vis spectra for a Ag nanofluid, b PVP-stabilized Ag nanofluid, $\mathbf{c}$ PVA-stabilized Ag nanofluid, and $\mathbf{d}$ PVA-PVP-stabilized Ag nanofluid using individual PVP, PVA, and blended polymer PVP-PVA surfactants are shown in Fig. 1. Each spectrum shows an absorption $\lambda_{\max }$ in the range of $420-430 \mathrm{~nm}$. The apparent blue shift in the absorption maximum of the Ag nanofluids due to the electronic transition and quantum size effect has been found in all the samples. The extent of the blue shifts in the absorption maximum for the nanofluids is surfactant dependent. In the case of PVA-stabilized Ag nanofluids, it exhibits a characteristic absorption maximum at $429 \mathrm{~nm}$ corresponding to $\pi-\pi^{*}$ electronic transitions, whereas a relatively weak absorption maximum at $421 \mathrm{~nm}$ for PVPstabilized Ag nanofluids is mainly attributed to the $n-\pi^{*}$, the electronic transition between the lone pair of oxygen and the vacant $\pi^{*}$ orbital of the pyrrolidone ring. A similar trend was observed in the case of polymer blends, and a broad and intense absorption maximum at $426 \mathrm{~nm}$ corresponds to $n \rightarrow \pi^{*}$ and $\pi-\pi^{*}$ electronic transitions $[32,33]$.

Figure 2 shows the FESEM images of Ag nanofluids stabilized by polymer and blended polymer dispersants. All the images exhibited uniform distributed spherical morphology of Ag nanoparticles. It indicates that the polymer dispersants played a crucial role in the uniform distribution of nanofluids in the system. This is mainly due to the formation of the electrostatic effect produced between the particles and the dispersants, which hinders the formation of clusters. It is well attested by the DLS analysis.
Fig. 2 FESEM images for a Ag nanofluid, b PVA-stabilized Ag nanofluid, $\mathbf{c}$ PVP-stabilized Ag nanofluid and d PVA-PVPstabilized Ag nanofluid

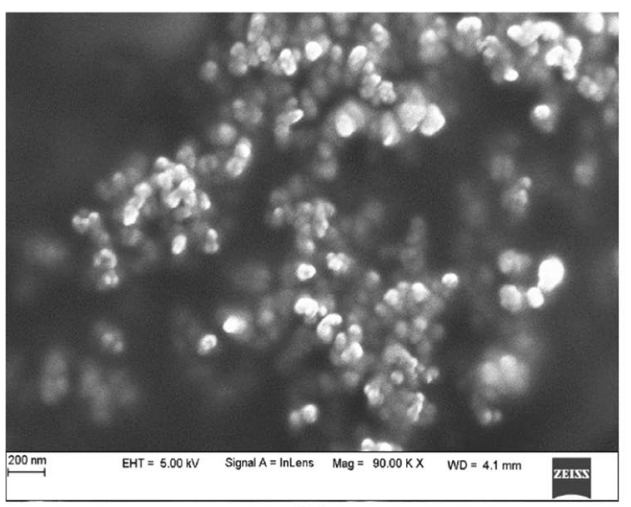

(a)

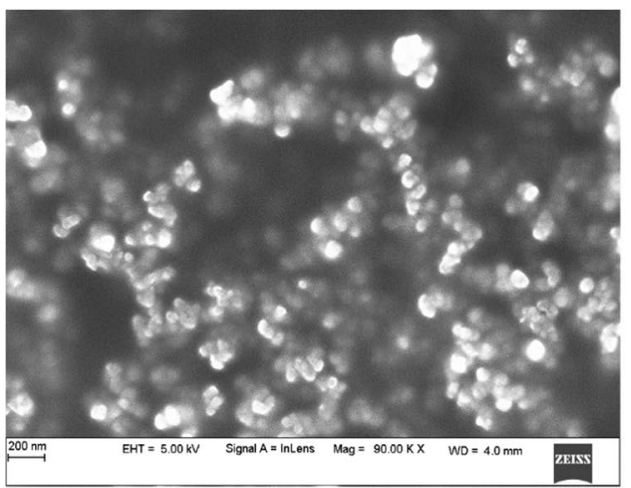

(c)

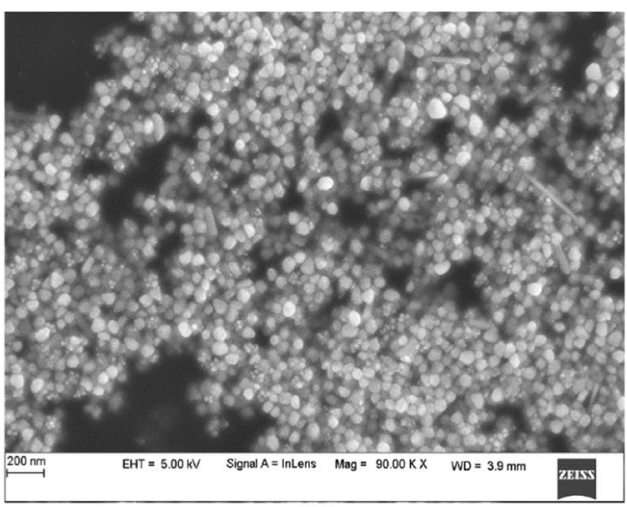

(b)

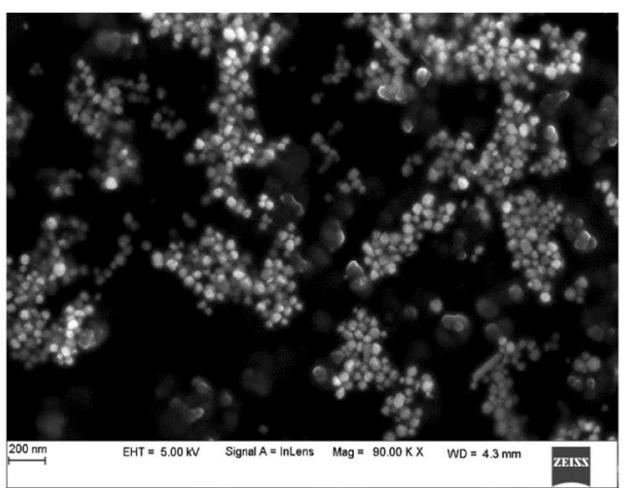

(d) 
The hydrodynamic size of the Ag nanoparticles was depicted by dynamic light scattering using a photon correlation spectrometer. An average particle size distribution of $\mathrm{Ag}$ nanofluids was analysed by using the DLS technique, and the graphs are shown in Fig. 3. The average particle size diameter of Ag nanofluid is found to be $28 \mathrm{~nm}$ and the poly dispersity index, the measure of the width of particle size distribution is 0.660 as shown in the Fig. 3a. The Ag nanofluids stabilized with PVA, PVP, and PVA-PVP polymer blend dispersants are represented in Fig. 3b-d. The average particle size diameter for dispersant-stabilized nanofluids is found in the range of $112 \mathrm{~nm}, 81 \mathrm{~nm}$, and $78 \mathrm{~nm}$, respectively. The average diameter of dispersant stabilized nanofluids is much higher than that of Ag nanofluids. It indicates that the formation of the dispersant layer on the surface of the NPs to produces a thermodynamically stable particle cluster. The polydispersity index of dispersant-stabilized nanofluids is $0.256,0.434$ and 0.497 implying the stability of the nanofluids. According to the literature, there will be instability in the system when the polydispersity index (PDI) is higher than 0.6 [34].

The present study revealed that while adding the surfactant into the Ag nanofluids, the polydispersity index was decreased; it indicates that the dispersants showed an active role for the dispersion of Ag nanofluids due to electro-steric hindrance produces between the adsorbed layer of the polymer and the nanoparticles in the suspension. It is further confirmed by using zeta potential data.

\section{Zeta potential}

Zeta potential value indicates an electric charge on the surface of the NPs; if it is more positive than $+30 \mathrm{mV}$ or more negative than $-30 \mathrm{mV}$, it is generally considered as a stable colloidal system [30]. The zeta potential value for with and without stabilized Ag nanofluids is represented in Fig. 4. The zeta potential value for the absence of dispersant showed $-18.3 \mathrm{mV}$; moreover, the potential values slightly change negative to positive values with an addition of polymer dispersants like PVA, PVP, and PVA-PVP blends, i.e. $21.6 \mathrm{mV}$, $34.2 \mathrm{mV}$, and $41.6 \mathrm{mV}$, respectively. It is because an adsorbed layer of the polymer dispersant on the cationic surface of the $\mathrm{Ag}$ nanoparticles creates an effective steric barrier between the particles, which ensures high stability and dispersibility.

\section{Rheological properties of nanofluids}

\section{Thermal conductivity of Ag nanofluids}

Uncertainty calculation The uncertainty of experimental results was determined from the instrument and precision error resulting from the deviation in the experimental dataset. The instrument error in the measurement of thermal conductivity by KD2 Pro is $\pm 5 \%$ [35]. The accuracy of the weighing scale is $0.001 \mathrm{~g}$. The uncertainty of the experiment data is obtained by the following [36]:

$\mu= \pm \sqrt{\left(\mu_{\mathrm{B}}\right)^{2}+\left(\mu_{\mathrm{p}}\right)^{2}}$ with $\mu_{\mathrm{p}}= \pm t_{\mathrm{v}, \mathrm{p}} \mathrm{SD}$

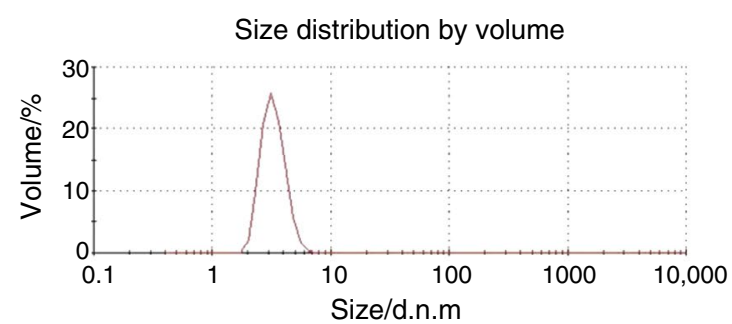

(a)

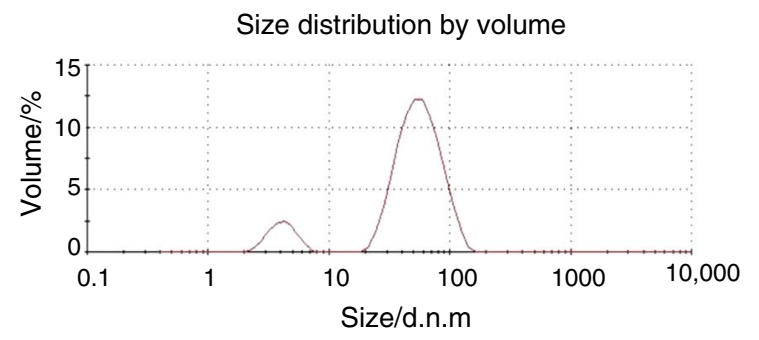

(c)

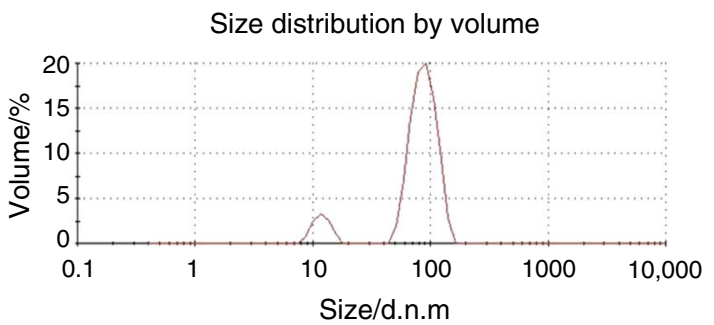

(b)

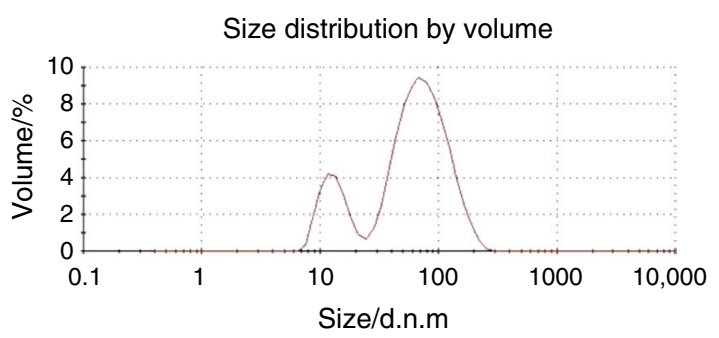

(d)

Fig. 3 DLS images for a Ag nanofluids, $\mathbf{b}$ stabilized with PVP, $\mathbf{c}$ stabilized with PVA, and $\mathbf{d}$ stabilized with PVP-PVA polymer blend dispersant 


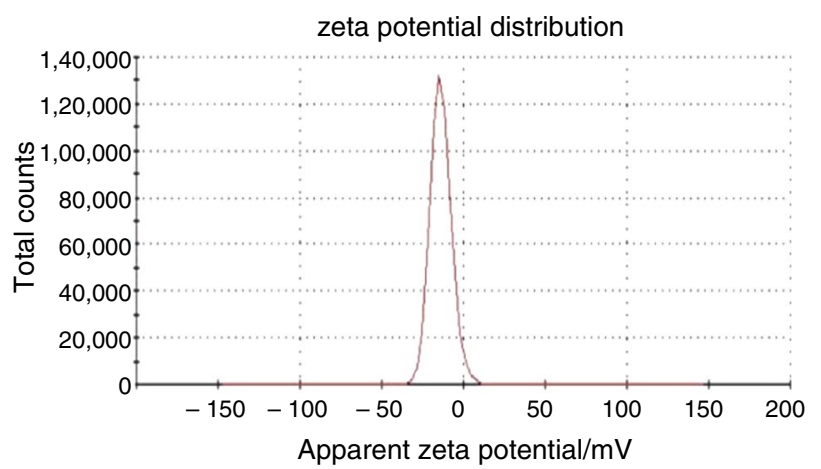

(a)

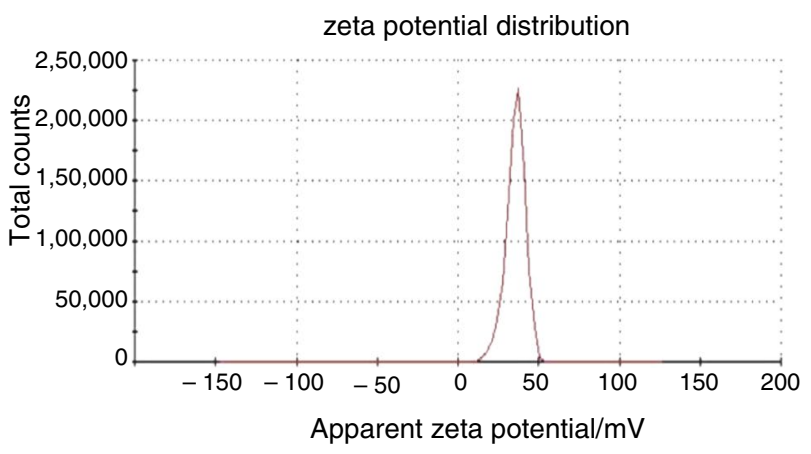

(c)

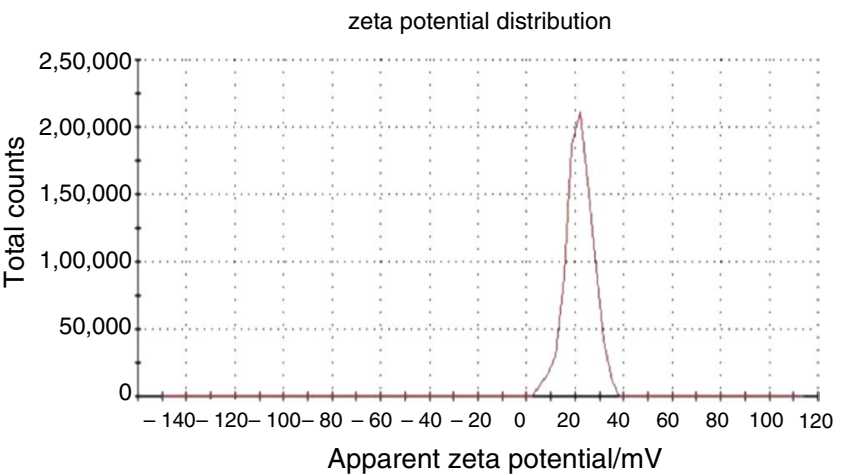

(b)

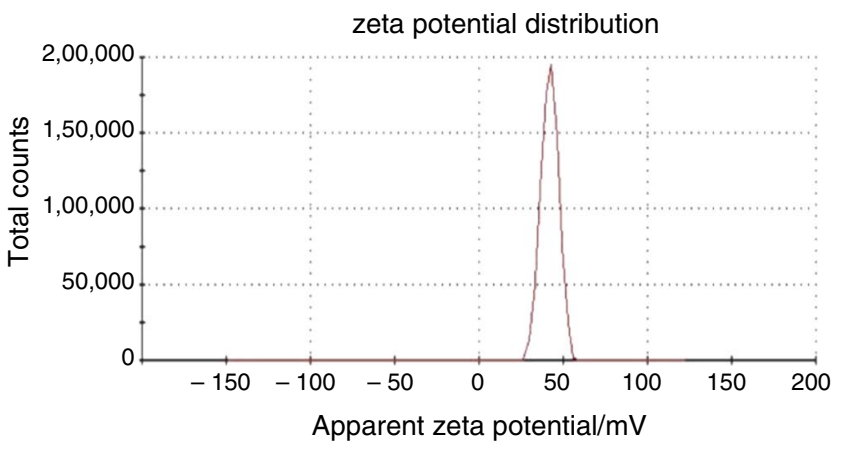

(d)

Fig. 4 Zeta potential images for Ag nanofluids a without dispersant, b stabilized with PVP, $\mathbf{c}$ stabilized with PVA, d stabilized with PVP-PVA mixed dispersant

where $\mu_{\mathrm{B}}, \mu_{\mathrm{p}}, t_{\mathrm{v}, \mathrm{p}}$ and SD are bias error, precision or random error in the measurement with $p \%$ probability, weighing function $\vartheta$ degree of freedom and sample standard deviation, respectively.

$u_{\mathrm{TCR}}=\left[\left(\frac{\delta k_{\mathrm{eff}}}{k_{\mathrm{f}}}\right)^{2}+\left(\frac{-k_{\mathrm{eff}}}{\left[k_{\mathrm{f}}\right]^{2}} \delta k_{\mathrm{f}}\right)^{2}\right]^{0.5}$

where $\delta k_{\text {eff }}$ and $\delta k_{\mathrm{f}}$ are uncertainty at $p \%$ probability, including both instrument and precision errors associated with the measured effective thermal conductivity and thermal conductivity of nanofluids, respectively. Finally, the uncertainty in the effective thermal conductivity and TCR (thermal conductivity ratio) was found to be between 0.5 and $3.23 \%$.

Influence of polymer dispersants on thermal conductivity of nanofluids The thermal conductivity of $\mathrm{Ag}$ nanofluids measured between 303.15 and $318.15 \mathrm{~K}$ with a different concentration ratio of dispersant and constant mass\% of $\mathrm{Ag}$ nanofluids (1:1-5:1 mass\%) is shown in Fig. 5. Error bars in the figure indicate the standard deviation of thermal conductivity data, and the linear fit curves are provided for visualization purpose. The obtained stand- ard deviation errors are tabulated in Table 1. The result shows that the thermal conductivity of the Ag nanofluids increases with both the temperature and the concentration of the polymer dispersants. The enhancing effect of temperature on thermal conductivity may be attributed to the increased intensity of the Brownian motion of NPs due to the increase in temperature. The microscopic motion of suspended NPs due to Brownian, van der Waals, and electrostatic forces plays a crucial role. Nanofluids exhibit higher thermal conductivity than their base fluids, even at very low concentrations of suspended NPs. Thermal conductivity of fluids is enhanced by both static and dynamic factors [16]. Brownian motion is caused by a random bombardment of fluid molecules, which causes the particles to move randomly through the liquid, allowing more heat transport between the particles and the fluids $[37,38]$. This translates into increased effective thermal conductivity. Jang and Choi [39] explained the enhancement of thermal conductivity of nanofluids as a function of temperature. The increase in temperature increases the Brownian motion significantly due to increase in collisions between the NPs. From Fig. 5a, b, it is observed that the thermal conductivity of PVA- and PVP-stabilized Ag nanofluids increases with an increase in temperature and dispersant 


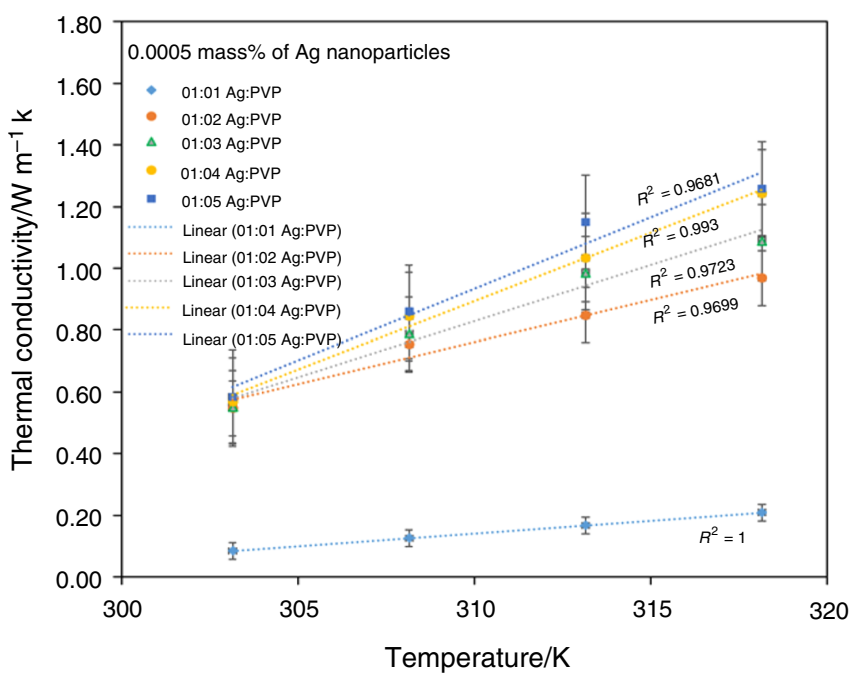

(a)

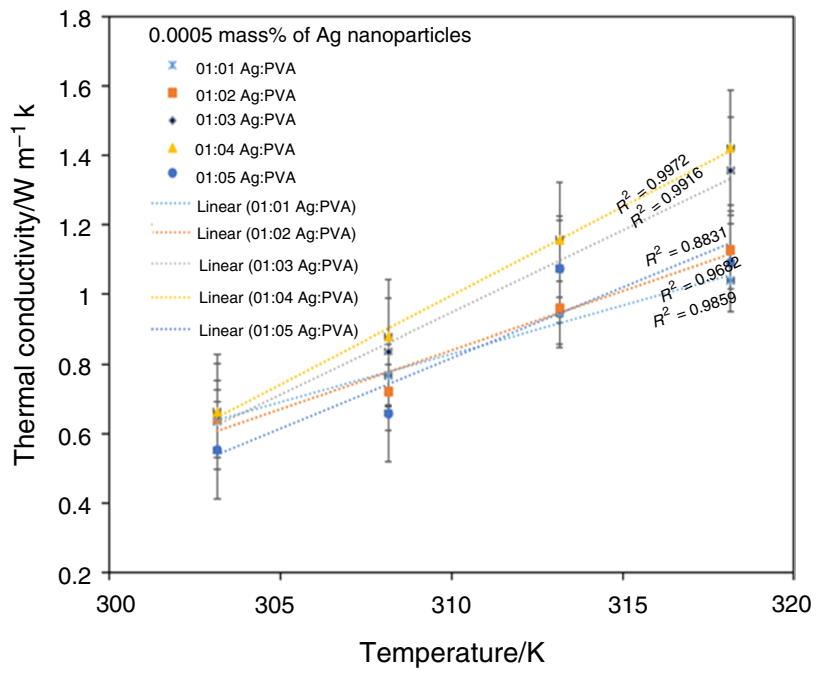

(b)

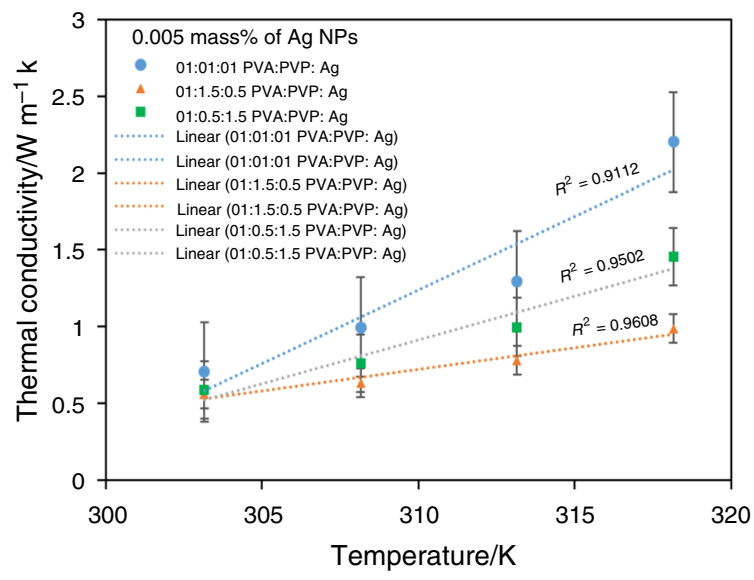

(c)

Fig. 5 Thermal conductivity measurement of Ag nanofluids stabilized by a PVP, b PVA, and $\mathbf{c}$ PVP-PVA blend polymer dispersant at different ratios. Error bar indicates the standard deviation

Table 1 Thermal conductivity and uncertainty values for $\mathrm{Ag}$ nanofluids

\begin{tabular}{|c|c|c|c|c|c|c|c|}
\hline \multirow[t]{2}{*}{ Temperature/K } & \multirow[t]{2}{*}{ Mass\% Ag NPs } & \multicolumn{2}{|c|}{$\begin{array}{l}\text { Mass\% of disper- } \\
\text { sants }\end{array}$} & \multicolumn{2}{|c|}{$\begin{array}{l}\text { Thermal } \\
\text { conductivity/W m }{ }^{-1} \mathrm{~K}\end{array}$} & \multicolumn{2}{|c|}{$\begin{array}{l}\text { Standard devia- } \\
\text { tion/error }\end{array}$} \\
\hline & & PVA & PVP & PVA & PVP & PVA & PVP \\
\hline 303.15 & 0.005 & 1 & 1 & 0.663 & 0.589 & 0.729 & 1.573 \\
\hline 308.15 & & 2 & 2 & 0.878 & 0.860 & 1.349 & 1.050 \\
\hline 313.15 & & 3 & 3 & 1.157 & 1.151 & 0.953 & 1.343 \\
\hline 318.15 & & 4 & 4 & 1.421 & 1.259 & 3.239 & 0.819 \\
\hline
\end{tabular}

concentration up to 4 mass $\%$. The thermal conductivity of Ag nanofluids decreased with an increase in dispersant concentration. This is mainly due to the increase in the interfacial thermal resistance between the particles and the fluids resulting from the excessive addition of adsorbed molecules. By increasing the dispersant concentration, the molecular size and steric repulsion have been increased, which in turn reduces the repulsive interaction and lower adsorption; this may lead to agglomeration.

The effect of blend polymer dispersants on the thermal conductivity of Ag nanofluids with three different concentration ratios is shown in Fig. 5c. An equimolar ratio of 
dispersant-stabilized Ag nanofluids exhibits the highest thermal conductivity compared to the relative dispersant ratio (1:1.5:0.5 and 1:0.5:1.5). Better dispersibility achieved by blend polymer dispersants having an equimolar ratio of PVP-PVA creates a strong electrostatic and steric effect in the system. The maximum thermal conductivity enhancement was observed for the Ag nanofluids stabilized with the equimolar concentration of mixed dispersant ratio compared to Ag nanofluids, which were stabilized by individual polymeric dispersants, i.e. $2.202 \mathrm{~W} \mathrm{~m}^{-1} \mathrm{~K}$ as compared to 1.421 and $1.229 \mathrm{~W} \mathrm{~m}^{-1} \mathrm{~K}$ for PVA and PVP at $318.15 \mathrm{~K}$, respectively.

Figure 6 shows the thermal conductivity ratio $\left(K_{\mathrm{nf}} / K_{\mathrm{f}}\right.$, i.e. ratio of thermal conductivity of the nanofluid to that of the base fluid) for the Ag nanofluids stabilized with equimolar ratio of blend polymer dispersant as a function of temperature (303.15-318.15 K) and a particle loading of 0.005 mass\%. The experimentally determined thermal conductivity of nanofluids was used to compare with the existing classical models proposed by Xuan et al. [40] and Kumar et al. [41], respectively. These two models describe the thermal conductivity of nanofluids as a function of temperature and Brownian motion of the NPs [41].

Xuan et al. developed a modified formula that is based on the Maxwell model for effective thermal conductivity of nanofluids.

$k_{\text {eff }}=\frac{k_{\mathrm{p}}+2 k_{\mathrm{b}}-\left(2 k_{\mathrm{b}}-k_{\mathrm{p}}\right) \emptyset}{k_{\mathrm{p}}+2 k_{\mathrm{b}}+\left(k_{\mathrm{b}}-k_{\mathrm{p}}\right) \emptyset} k_{\mathrm{b}}+\frac{\rho_{\mathrm{p}} \emptyset C_{\mathrm{p}}}{2} \sqrt{\frac{k_{\mathrm{B}} T}{3 \pi r_{\mathrm{c}} \mu}}$

where $k_{\mathrm{B}}$ is Boltzmann constant $\left(1.381 \times 10^{-23} \mathrm{~J}^{-1} \mathrm{~K}\right), r_{\mathrm{c}}$ is apparent radius of cluster ( $35 \AA$ ) , $k_{\mathrm{p}}\left(191.32 \mathrm{~W} \mathrm{~m}^{-1} \mathrm{~K}\right.$ ) and $k_{\mathrm{b}}\left(0.599 \mathrm{~W} \mathrm{~m}^{-1} \mathrm{~K}\right)$ are the thermal conductivities of

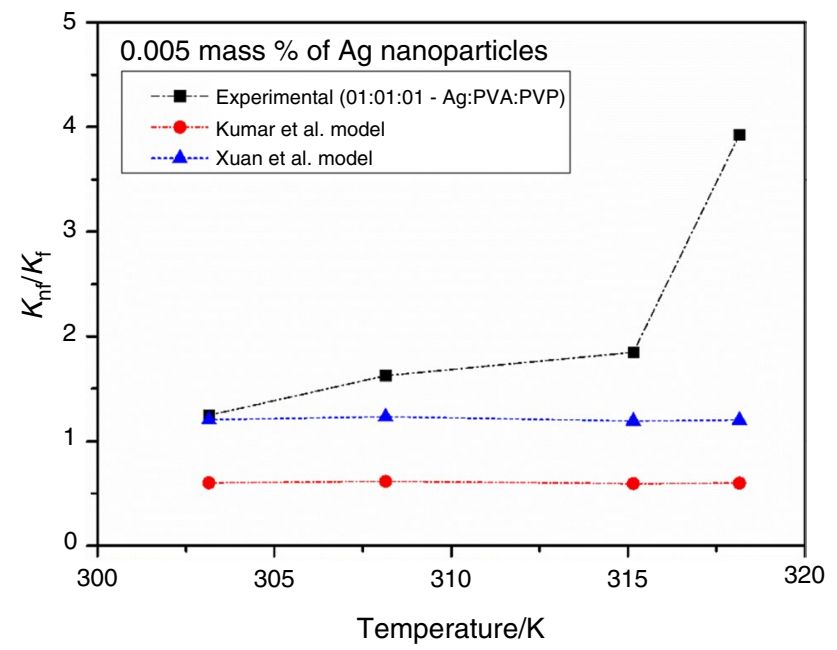

Fig. 6 Variation of thermal conductivity ratio with polymer blend surfactant at different temperatures compared with Kumar and Xuan et al. models nanoparticle and the base fluid, $C_{\mathrm{p}}$ specific heat capacity $\left(4.186 \mathrm{~J}^{-1} \mathrm{~kg}{ }^{\circ} \mathrm{C}\right)$, respectively.

Kumar et al. proposed a comprehensive model for the effective thermal conductivity of nanofluids combining of two sub-classical models, i.e. stationary particle model derived from the Fourier's law of diffusion and moving particle model deduced from the Stokes-Einstein formula following the strong temperature dependence for the enhancement of thermal conductivity in nanofluids. It is expressed as:

$k_{\mathrm{eff}}=k_{\mathrm{b}}+C_{\mathrm{p}} \frac{2 k_{\mathrm{B}} T}{\pi \vartheta d_{\mathrm{p}}^{2}} \frac{\emptyset r_{\mathrm{b}}}{k_{\mathrm{b}}(1-\emptyset) r_{\mathrm{p}}} k_{\mathrm{b}}$

where $C_{\mathrm{p}}$ is heat constant $\left(4.186 \mathrm{~J}^{-1} \mathrm{~kg}{ }^{\circ} \mathrm{C}\right), \vartheta$ dynamic viscosity of the base fluid $\left(9.375 \times 10^{-4} \mathrm{~Pa} \cdot \mathrm{s}\right)$, and $d_{\mathrm{p}}$ diameter of the particles $(78 \mathrm{~nm})$.

The experimental findings were compared with the Kumar et al. and Xuan et al. models as shown in Fig. 6. The results showed good agreement with the Xual et al. model at lower temperature $(303.15 \mathrm{~K})$ and are deviated at higher temperatures. However, the experimental values are not showing good agreement with the Kumar et al. model, which may be due to the addition of surfactants and variation in the temperature, which in turn intensify the Brownian motion of the NPs. The increase in Brownian motion of NPs leads to the increase in micro-convection heat transfer, which reduces the viscosity of the fluids which results in the increase in thermal conductivity of nanofluids [42-45]. Previous literature reported that the maximum thermal conductivity of $13.42 \%$ for PVP [46] and $28 \%$ for the mixture of oleic acid and potassium oleate [1] as dispersants for the stabilization of $\mathrm{Ag}$ nanofluids. However, in this present study we have observed about $31.47 \%$ enhancement of thermal conductivity at equimolar ratio of blend polymer dispersant-stabilized Ag nanofluids. The blend polymer dispersants had better dispersibility than the linear electrolytes due to amphiphilic characteristics, the hydrophobic part (pyrrolidone moiety in PVP) is strongly adsorbed on the surface of the metal core, and hydrophilic chain (hydroxyl moiety in PVA) produces a strong steric repulsive barrier between the NPs which results in the reduction in particle aggregation.

\section{Conclusions}

Ag nanofluids were successfully synthesized by a costeffective single-step wet chemical method to obtain monodisperse nanoparticles, which are used for the preparation of Ag nanofluids by varying concentration ratio of PVA, PVP and blend polymer dispersants in water as base fluids. From the experimental investigation, it is revealed that higher thermal conductivity was observed at equimolar ratio 
of blend polymer dispersant-stabilized Ag nanofluids and gradually decreases with the increase in the concentration of the dispersants; this is mainly due to the formation of flocculation created by the PVP and PVA chains. 31.47\% efficiency of thermal conductivity was observed at lower particle concentration (0.005 mass\%). Xuan model is a corresponding agreement with the experimentally calculated values at $303.15 \mathrm{~K}$.

Acknowledgements We acknowledge the Manipal Institute of Technology, Manipal College of Pharmaceutical Sciences, and Manipal Academy of Higher Education, Manipal, for providing the facility to conduct the research work.

Funding Open access funding provided by Manipal Academy of Higher Education, Manipal.

Open Access This article is licensed under a Creative Commons Attribution 4.0 International License, which permits use, sharing, adaptation, distribution and reproduction in any medium or format, as long as you give appropriate credit to the original author(s) and the source, provide a link to the Creative Commons licence, and indicate if changes were made. The images or other third party material in this article are included in the article's Creative Commons licence, unless indicated otherwise in a credit line to the material. If material is not included in the article's Creative Commons licence and your intended use is not permitted by statutory regulation or exceeds the permitted use, you will need to obtain permission directly from the copyright holder. To view a copy of this licence, visit http://creativecommons.org/licenses/by/4.0/.

\section{References}

1. Parametthanuwat T, Bhuwakietkumjohn N, Rittidech S, Ding Y. Experimental investigation on thermal properties of silver nanofluids. Int J Heat Fluid Flow. 2015;56:80-90.

2. Gherasim O, Ficai A, Andronescu E. Biomedical applications of silver nanoparticles: an up-to-date overview. Nanomaterials. 2018;8:1-25.

3. Islam MR, Shabani B, Rosengarten G. Nanofluids to improve the performance of PEM fuel cell cooling systems: a theoretical approach. Appl Energy. 2016;178:660-71.

4. Hussein AM, Sharma KV, Bakar RA, Kadirgama K. The effect of nanofluid volume concentration on heat transfer and friction factor inside a horizontal tube. J Nanomater. 2013. https://doi. org/10.1155/2013/859563.

5. Rahmatolahzadeh Reza, Aliabadi Majid, Motevalli Kourosh. $\mathrm{Cu}$ and $\mathrm{CuO}$ nanostructures: facile hydrothermal synthesis, characterization, and photocatalytic activity using new starting reagents. J Mater Sci: Mater Electron. 2017;28:148-56.

6. Vidhu VK, Philip D. Photosynthesis and application of bioactive $\mathrm{SiO}_{2}$ nanoparticles. Mater Charact. 2015;101:97-105.

7. Purkait T, Singh G, Kumar D, Singh M, Dey RS. High-performance flexible supercapacitors based on electrochemically tailored three-dimensional reduced graphene oxide networks. Sci Rep. 2018;1:1-13.

8. Jaiswal AK, Sikarwar S, Singh S, Dey KK, Yadav BC, Yadav RR. Fabrication of nanostructured magnesium ferrite polyhedrons and their applications in heat transfer management and gas/ humidity sensors. J Mater Sci: Mater Electron. 2019. https://doi. org/10.1007/s10854-019-01099-1.
9. Li D, Fang W, Feng Y, Geng Q, Song M. Stability properties of water-based gold and silver nanofluids stabilized by cationic gemini dispersants. J Taiwan Inst Chem Eng. 2019;97:458-65.

10. Babita, Sharma SK, Gupta SM. Preparation and evaluation of stable nanofluids for heat transfer application: a review. Exp Therm Fluid Sci. 2016;79:202-12.

11. Mirzaei H, Darroudi M. Zinc oxide nanoparticles: biological synthesis and biomedical applications. Ceram Int. 2017;43:907-14.

12. Chakraborty S, Sarkar I, Behera DK, Pal SK, Chakraborty S. Experimental investigation on the effect of dispersant addition on thermal and rheological characteristics of $\mathrm{TiO}_{2}$ nanofluid. Powder Technol. 2017;307:10-24.

13. Abdel RE, et al. Stability and electrical conductivity of waterbased $\mathrm{Al}_{2} \mathrm{O}_{3}$ nanofluids for different applications. HBRC J. 2016;12:227-34.

14. Chen M, He Y, Zhu J, Shuai Y, Jiang B, Huang Y. An experimental investigation on sunlight absorption characteristics of silver nanofluids. Sol Energy. 2015;115:85-94.

15. Singh Ashok K, Raykar Vijay S. Microwave synthesis of silver nanofluids with polyvinylpyrrolidone (PVP) and their transport properties. Colloid Polym Sci. 2008. https://doi.org/10.1007/ s00396-008-1932-9.

16. Murshed SMS, Leong KC, Yang C. Thermophysical and electrokinetic properties of nanofluids: a critical review. Appl Therm Eng. 2008;28:2109-25.

17. Saleh R, Putra N, Wibowo RE, et al. Titanium dioxide nanofluids for heat transfer applications. Exp Therm Fluid Sci. 2014;52:19-29.

18. Xia Guodong, Jiang Huanming, Liu Ran, Zhai Yuling. Effects of surfactant on the stability and thermal conductivity of $\mathrm{Al}_{2} \mathrm{O}_{3}$ / de-ionized water nanofluids. Int J Ther Sci. 2014;84:118-24.

19. Sagitha P, Sarada K, Muraleedharan K. One-pot synthesis of polyvinyl alcohol (PVA) supported silver nanoparticles and its efficiency in catalytic reduction of methylene blue. Trans Nonferrous Met Soc China. 2016;26:2693-700.

20. Pavithra KS, Fasiulla Yashoda MP, Prasannakumar S. Synthesis, characterization and thermal conductivity of $\mathrm{CuO}$ : water-based nanofluids with different dispersants. Part Sci Technol. 2019. https://doi.org/10.1080/02726351.2019.1574941.

21. Wang L, Kang Y, Liu X, Zhang S, Huang W, Wang S. ZnO nanorod gas sensor for ethanol detection. Sens Actuators B Chem. 2012;162:237-43.

22. Ahammed N, Asirvatham LG, Wongwises S. Effect of volume concentration and temperature on viscosity and surface tension of graphene-water nanofluid for heat transfer applications. J Therm Anal Calorim. 2015;123:1399.

23. Sadri R, Ahmadi G, Togun H, Dahari M, Kazi S, Sadeghinezhad E, Zubir N. An experimental study on thermal conductivity and viscosity of nanofluids containing carbon nanotubes. Nanoscale Res Lett. 2014. https://doi.org/10.1186/1556-276X-9-151.

24. Chen L, Xie H. Properties of carbon nanotube nanofluids stabilized by cationic gemini dispersant. Thermochim Acta. 2010;506:62-6.

25. Adil M, Zaid HM, Chuan LK, Latiff NRA. Effect of dispersion stability on electrorheology of water-based $\mathrm{ZnO}$ nanofluids. Energy Fuels. 2016;30:6169-77.

26. Babita, Sharma S, Gupta SM. Preparation and evaluation of stable nanofluids for heat Transfer application: a review. Exp Therm Fluid Sci. 2016. https://doi.org/10.1016/j.expthermfl usci.2016.06.029.

27. Wusiman K, Jeong H, Tulugan K, Afrianto H, Chung H. Thermal performance of multi-walled carbon nanotubes (MWCNTs) in aqueous suspensions with surfactants SDBS and SDS. Int Commun Heat Mass Transf. 2013;41:28-33.

28. Acosta EJ, Mesbah A, Tsui T. Surface activity of mixtures of dodecyl trimethyl ammonium bromide with sodium 
perfluorooctanoate and sodium octanoate. J Dispers Deterg. 2006;9:367-76.

29. Hosseini SS, Teoh MM, Chung TS. Hydrogen separation and purification in membranes of miscible polymer blends with interpenetration networks. Polymer. 2008;49:1594.

30. Sharma SK, Gupta SM. Synergic effect of SDBS and GA to prepare stable dispersion of CNT in water for industrial heat transfer applications. Mater Res Express. 2018. https://doi. org/10.1088/2053-1591/aac579.

31. Kreibig U, Vollmer M. Optical properties of metal clusters. Berlin: Springer; 1994.

32. Trügler A. Optical properties of metallic nanoparticles. Berlin: Springer; 2016.

33. Choudhary S, Sengwa RJ. ZnO nanoparticles dispersed PVAPVP blend matrix based high performance flexible nanodielectrics for multifunctional microelectronic devices. Curr Appl Phys. 2018. https://doi.org/10.1016/j.cap.2018.05.023.

34. Kumar S, Gradzielski M, Mehta SK. The critical role of surfactants towards CdS nanoparticles: synthesis, stability, optical and PL emission properties. RSC Adv. 2013;3:2662-76.

35. Paul G, Sarkar S, Pal T, Das PK, Manna I. Concentration and size dependence of nano-silver dispersed water-based nanofluids. J Colloid Interface Sci. 2012;371:20-7.

36. Hina S, Juan D, Priyanka S, Hoo YT. Ecofriendly synthesis of silver and gold nanoparticles by Euphrasia officinalis leaf extract and its biomedical applications. Artif Cells Nanomed Biotechnol. 2017. https://doi.org/10.1080/21691401.2017.1362417.

37. Sharifpur M, Tshimanga N, Meyer JP, Manca O. Experimental investigation and model development for thermal conductivity of $\alpha-\mathrm{Al}_{2} \mathrm{O}_{3}$-glycerol nanofluids. Int Commun Heat Mass Transf. 2017;85:12-22.
38. Bhanushali S, Jason NN, Ghosh P, Ganesh A, Simon GP. Enhanced thermal conductivity of copper nano fluids: the effect of filler geometry. ACS Appl Mater Interfaces. 2017;9:18925-35.

39. Jang SP, Choi SUS. Role of Brownian motion in the enhanced thermal conductivity of nanofluids. Appl Phys Lett. 2004;84:4316-8.

40. Xuan Yimin, Li Qiang, Weifeng Hu. Aggregation structure and thermal conductivity of nanofluids. Thermodynamics. 2003;49:1038-43.

41. Kumar DH, Patel HE, et al. Model for heat conduction in nanofluids. Phys Rev Lett. 2003;14:144301.

42. Qiu Lin, Zhu Ning, Feng Yanhui, et al. A review of recent advances in thermophysical properties at the nanoscale: from solid state to colloids. Phys Rep. 2020;843:1-81.

43. Murshed SMS, Leong KC, Yang C. Investigations of thermal conductivity and viscosity of nanofluids. Int J Therm Sci. 2008;47:560-8.

44. Zeroual Soukaina, Estellé Patrice, Cabaleiro David, et al. Ethylene glycol based silver nanoparticles synthesized by polyol process: characterization and thermophysical profile. J Mol Liq. 2020;310:113229.

45. Marcos Marco A, Cabaleiro David, Hamze Samah, et al. NePCM based on silver dispersions in poly(ethylene glycol) as a stable solution for thermal storage. Nanomaterials. 2019;10:3-22.

46. Zhang L, Yu W, Zhu D, Xie H, Huang G. Enhanced thermal conductivity for nanofluids containing silver nanowires with different shapes. J Nanomaterials. 2017;2017:5802016.

Publisher's Note Springer Nature remains neutral with regard to jurisdictional claims in published maps and institutional affiliations.

\section{Affiliations}

\section{K. S. Pavithra ${ }^{1} \cdot$ S. C. Gurumurthy ${ }^{2} \cdot$ M. P. Yashoda ${ }^{1}\left[\right.$ Tarun Mateti $^{3} \cdot$ Koduri Ramam $^{4} \cdot$ Roopa Nayak $^{5} \cdot$ M. S. Murari $^{6}$}

1 Department of Chemistry, Manipal Institute of Technology, Manipal Academy of Higher Education Manipal, Udupi, Karnataka, India

2 Nanomaterials and Polymer Physics Lab., Department of Physics, Manipal Institute of Technology, Manipal Academy of Higher Education Manipal, Udupi, Karnataka, India

3 Department of Chemical Engineering, Manipal Institute of Technology, Manipal Academy of Higher Education Manipal, Udupi, Karnataka, India
4 Departamento de Ingeniería de Materiales (DIMAT), Facultad de Ingeniería (FI), Universidad de Concepción (UdeC), Concepción, Chile

5 Department of Biotechnology, Manipal School of Life Sciences, Manipal Academy of Higher Education Manipal, Udupi, Karnataka, India

6 DST Purse Lab, Mangalore University, Mangalagangotri, India 